\title{
Integration strategies for caring for chronic noncommunicable diseases: a case study
}

Estratégias de integração dos cuidados às doenças crônicas não transmissíveis: estudo de caso

Estrategias de integración para la atención de enfermedades crónicas no transmisibles: estudio de caso

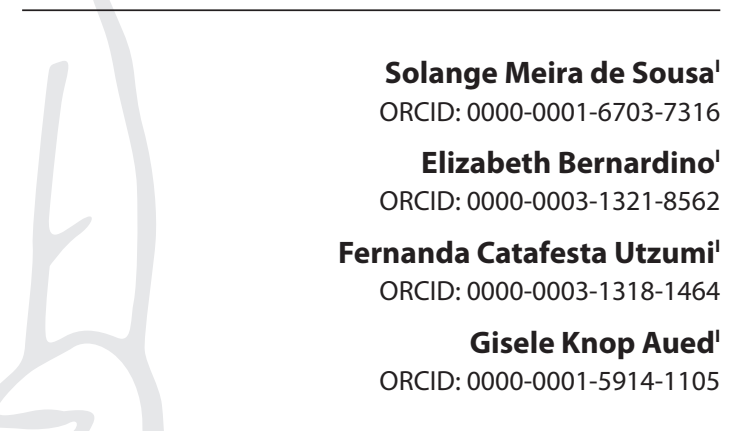

'Universidade Federal do Paraná. Curitiba, Paraná, Brazil.

How to cite this article:

Sousa SM, Bernardino E, Utzumi FC, Aued GK. Integration strategies for caring for chronic noncommunicable diseases:

a case study. Rev Bras Enferm. 2021;74(1):e20190563. doi: http://dx.doi.org/10.1590/0034-7167-2019-0563

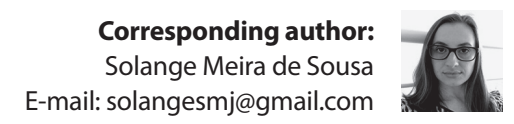

EDITOR IN CHIEF: Dulce Barbosa ASSOCIATE EDITOR: Fátima Helena Espírito Santo

Submission: $12-30-2019$

Approval: 09-13-2020

\begin{abstract}
Objectives: to identify the strategies for integrated care used regarding Chronic Noncommunicable Diseases in a Health District. Methods: a case study developed in a district of a municipality in southern Brazil, with 34 participants (coordinators and nursing assistants). Data were collected between August 2016 and June 2017, through interviews, documents and computerized files. To organize the data, the MAXQDA" software was used. Analysis took place using the Integrated Care Network model. Results: integration strategies were highlighted in the systemic, normative and functional dimensions, such as coordination district organization, Annual Operating Plan, information system, and user management service. Final Considerations: the district comprises a structure that enables interactions through various tools; among these, coordination represents an effective strategy to enhance care, boost cooperation among professionals and support and manage the district.

Descriptors: Comprehensive Health Care; Chronic Disease; Nurses; Case Reports; Health Services Administration.
\end{abstract}

\section{RESUMO}

Objetivos: identificar as estratégias para a integração dos cuidados utilizadas no contexto das Doenças Crônicas não Transmissíveis em um Distrito Sanitário. Métodos: estudo de caso desenvolvido em um distrito de um município da região Sul do Brasil, com 34 participantes (coordenadores e enfermeiros assistenciais). Os dados foram coletados entre agosto/2016 e junho/2017, por meio de entrevistas, documentos e arquivos computadorizados. Para organização dos dados, utilizou-se o software MAXQDA'. A análise ocorreu mediante o modelo de Rede Integrada de Cuidados. Resultados: destacaram-se estratégias de integração nas dimensões sistêmica, normativa e funcional, como as coordenações, organização do Distrito, Plano Operativo Anual, sistema de informação e serviço de gestão para o usuário. Considerações Finais: o distrito compreende uma estrutura que possibilita interações por meio de várias ferramentas; dentre essas, a coordenação representa uma estratégia eficaz para potencializar o cuidado, impulsionar a cooperação entre os profissionais e ser apoio e gestão ao distrito. Descritores: Cuidados Integrais de Saúde; Doenças Crônicas; Enfermeiras e Enfermeiros; Estudo de Caso; Gestão dos Serviços de Saúde.

\section{RESUMEN}

Objetivos: identificar las estrategias de integración de la atención utilizadas en el contexto de las Enfermedades Crónicas No Transmisibles en un Distrito de Salud. Métodos: estudio de caso desarrollado en un distrito de un municipio de la región sur de Brasil, con 34 participantes (coordinadores y auxiliares de enfermería). Los datos fueron recolectados entre agosto/2016 y junio/2017, a través de entrevistas, documentos y archivos computarizados. Para organizar los datos se utilizó el software MAXQDA ${ }^{\circ}$. El análisis se realizó utilizando el modelo Red de Atención Integrada. Consideraciones Finales: el distrito comprende una estructura que permite interacciones a través de varias herramientas; entre estos, la coordinación representa una estrategia eficaz para potenciar la atención, impulsar la cooperación entre profesionales y ser soporte y gestión del distrito.

Descriptores: Atención Integral de Salud; Enfermedad Crónica; Enfermeras y Enfermeros; Informes de Casos; Administración de los Servicios de Salud. 


\section{INTRODUCTION}

The right to health guaranteed by the Federal Constitution implies implementing policies to qualify health actions for the purpose of comprehensive care. This scenario is characterized by constant challenges, such as increased incidence of Chronic Noncommunicable Diseases (CNCDs), caused, among other aspects, by changes in the epidemiological profile resulting from the aging of the population. Fragmentation of care within a context where there is a scarcity of resources has required proactivity and flexibility of adaptation by health services ${ }^{(1-4)}$. The restructuring of care and the reorganization of the system in Health Care Networks (RAS - Rede de Atenção à Saúde), with articulated health actions and services, can contribute to comprehensive care ${ }^{(1)}$, with emphasis on Primary Health Care (PHC) as a care provider.

CNCDs account for more than $70 \%$ of global deaths, being among the agendas discussed and that demand resolution by the health sector. In 2016, approximately 41 million deaths occurred due to this problem, caused by cardiovascular disease (44\% of all deaths from CNCD), cancer (22\%), chronic respiratory disease $(9 \%)$ and diabetes $(4 \%)^{(5)}$. They have a long or uncertain duration, usually more than one etiology, they require continuous and individualized treatment, causing high costs to the health system, which requires initiatives to face them.

Over the past decade, different models and approaches for integrated care have been widely applied and documented in various settings, resulting in a multiplicity of definitions and conceptual structures. Each analyzed context uses a different meaning to the term, causing distortions on the knowledge of that subject. In a review in this regard ${ }^{(6)}, 175$ concepts were identified for the term, indicating that there is no single definition for integrated care, nor a form of perfect operation. Several studies have been developed to contribute to a better understanding on the subject, considering that the different perspectives in relation to integration are related to different authors and contexts ${ }^{(6-10)}$.

Considering the difficult management of CNCDs due to the complexity of problems, low resolution due to fragmentation of care and scarce resources, the role of institutions and professionals to act individually or collectively aiming at comprehensive care, and PHC as the organizer of health actions, the question emerged: how does health care integrate regarding CNCDs in a Health District?

\section{OBJECTIVES}

To identify the strategies for integrated care used regarding Chronic Noncommunicable Diseases in a Health District.

\section{METHODS}

\section{Ethical aspects}

All ethical aspects were followed in accordance with Resolution 466/12 of the Brazilian National Health Council (Conselho Nacional de Saúde). Data collection occurred after approval of the study and acceptance by participants. Personal contact was made, in which the study's objectives were clarified, as well as the relevance of the research. Subsequently, each professional was contacted and scheduled times and places were established according to their availability. At the time, the researchers read the Informed Consent Term, clarifying participants' doubts. If a participant agreed to participate in the study, authorization was requested by signing each participant after understanding. At the same time, they were asked about documents and computerized files consistent with the objectives, which was taken into account in this phase of the study ${ }^{(11)}$.

To present the results, all participants were identified by letters, followed by a number in ascending order, according to the order of the interviews. Thus, letter $\mathrm{N}$ was followed by a number to represent nursing assistants (N1, N2 ... N15); the letter C, followed by a number $(\mathrm{C} 1, \mathrm{C} 2 \ldots \mathrm{C} 15)$ to represent the coordinators of each health unit; and letter $\mathrm{G}$, followed by a number (G1 ... G4) to represent HD (Health District) coordinators and director. The data related to the interview, computerized documents and files are identified by letters "IN", " $C D$ " and "CF", respectively ${ }^{(11)}$.

\section{Theoretical framework}

In this study, the Integrated Care Network model(7) was adopted as a theoretical framework, which comprises integration, a process that involves creation and maintenance of a common structure between individuals and organizations - independent parties - in order to coordinate their interdependence to achieve a collective project ${ }^{(7)}$. This definition is in line with what the World Health Organization conceptualizes ${ }^{(12)}$, which considers integration as ways of interconnection and cooperation to provide care and guarantee continuity of care to individuals, with a view to efficiency in results.

From this perspective, integration is learned within an articulated context that favors an integrated system, based on the dimensions: Integrated care; Clinical team integration; Functional integration; Normative integration; Systemic integration. The first four relate to the interaction between individuals and interdependent organizations, and systemic integration establishes relationships between a local service and the Health System ${ }^{(7,11)}$.

\section{Type of study}

It is a single integrated case study, with a qualitative approach, developed in a HD of a municipality located in southern Brazil ${ }^{(11)}$. Integrated care in a HD was selected as the unit of analysis - the case to be studied ${ }^{(11,13)}$. The criteria described in the instrument Consolidated Criteria for Reporting Qualitative Research (COREQ) were adopted ${ }^{(14)}$.

\section{Methodological procedures}

Conducting a case study requires developing a protocol to guide data collection, increasing the reliability of the study and covering the expected evidence. Thus, the following aspects and/ or steps were defined and/or executed: theoretical and ethical aspects; contact with HD; guiding question; objective; analysis unit; theoretical proposition; logic that links the collected data to the propositions (data analysis by standard combination); 
conducting a pilot case in another HD to contribute to data collection organization refinement and instruments ${ }^{(11,13)}$.

\section{Study setting}

For this study, one of the HD of a municipality in southern Brazil was listed. The choice was intentional, considering that HD are regions that have the same characteristics in terms of functioning, composition of managers (coordinators) and connections with other services of the Network. Each HD has coordination of health management, health care and health surveillance as well as coordinators in each of the services ${ }^{(11)}$.

\section{Data source}

Participants were 34 professionals from a HD, intentionally selected, as they included key informants with management and care experience. Health care coordinators and nurses, such as health care coordinator, health surveillance coordinator, health management coordinator and local coordinators of each of the 15 $\mathrm{HD}$ and a nurse from each service were included. Professionals who had any leave during the data collection period were excluded ${ }^{(11)}$.

\section{Data collection and organization}

Data collection was carried out between August 2016 and June 2017, through interviews (primary sources), computerized documents and files (secondary sources) ${ }^{(11)}$. All instruments used for data collection included aspects related to the dimensions of integrated care in health, through a script built from the adopted theoretical framework ${ }^{(7,11)}$, with support from other relevant studies ${ }^{(9,11-12)}$.

The interviews were audio-recorded, with a maximum duration of 1 hour and 24 minutes and 31 seconds and a minimum of 18 minutes and 58 seconds. Through documentary analysis, resolutions, decrees and laws were verified. Among the documents, a field diary was used in order to take notes about the functioning of services, interactions among professionals, aspects related to the information system. The analysis of computerized files included electronic media materials available online. The interviews were transcribed, and their content as well as all the information resulting from the other sources of evidence were organized in analysis charts ${ }^{(11)}$.

The integrated care dimensions and its characteristics were constituted in the categories and subcategories of analysis, respectively, previously defined. To assist in the organization and categorization of data, MAXQDAं, 2018 was used ${ }^{(11)}$.

\section{Data analysis}

The information was grouped in analysis charts by means of categories and subcategories ${ }^{(11,13)}$, until it arrived in a more compact version with more significant aspects. For all sources of evidence, we sought to apprehend the aspects mentioned in the script taking into account data relevance, which made it possible to identify convergences between the information obtained ${ }^{(11)}$.

From the analysis guided by the theoretical framework and confronted with the theoretical proposition, an emphasis was established between the objective and the categories: Systemic integration (subcategory: Principles of organization of the health system are consistent with the local dynamics); Normative integration (subcategories: Cooperation between professionals to obtain continued care; Informal coordination mechanisms are essential; Care with a focus on users is an important norm and guides the behavior of professionals and services); Functional integration (subcategories: Health District management favors meeting health needs; Decisions by professionals consistent with the care project; Information system allows providing services favorable to continuity of care; User management service) $)^{(11)}$.

For purposes of analysis, the theoretical proposal of this study stands out ${ }^{11,13)}$ : "The guarantee of comprehensive care results from integration in the political, institutional, organizational and care plans. However, it is in a care plan that therapeutic project is operationalized through mechanisms for integrated care, such as referral and counter-referral care flows" ${ }^{\prime \prime 11)}$.

\section{RESULTS}

The results are described according to the integration dimensions and its defining characteristics related to the study's objective, i.e., categories and subcategories, respectively, followed or not by sources of evidence related to documents and computerized files. The defining characteristics are titled as they were originally described in data collection instruments. However, only some aspects consistent with the characteristics, which do not reach their totality, were recovered. Furthermore, due to insufficient data, not all characteristics were relevant or were considered.

Participants were predominantly female $(91.1 \%)$, aged 31 to 40 years $(41.1 \%)$, followed by $41-50$ years $(29.4 \%)$ and $51-61$ years $(29,4 \%)$; job tenure of 6 months- 2 years (38.2\%), 3-5 years (32.3\%), $8-10$ years $(20.5 \%)$ and $15-19$ years $(8.8 \%)$. Most participants were graduated in nursing $(91.1 \%)$, followed by pharmacy $(8.8 \%)$, and dentistry (2.9\%). Of these, $44.1 \%$ were unit coordinators and the same percentage (44.1\%) was nursing assistants; $11.7 \%$ were HD coordinators. It can be seen that the composition of coordinators as a whole is essentially that of nurses. As for training, all professionals have graduate degrees; of these, $94.1 \%$ lato sensu level (specialization) and 5.8\%, strictu sensu level (master's degree).

\section{Systemic integration}

\section{Principles of organization of the health system are consistent with the local dynamics}

The active participation of managers through information dissemination, training and their presence favors reciprocity of professionals and allows HD to be better involved with the network. The way in which managers do their work reflects positively in various contexts analyzed, especially in the work of local coordinators, stimulating their practices and providing the basis for them to direct their teams towards a differentiated, complete service with little margin for failure.

Also, in this list, SUS (Sistema Único de Saúde -Brazilian Unified Health System) guidelines and principles that support professional work could be highlighted, even though they have not been 
detailed by professionals, being, in fact, the foundation for health work to respond to users' needs. Ignorance about principles and guidelines is recurrent in many statements. Moreover, it is difficult to reconcile these principles with daily actions, to understand care flows and to dynamize assistance, in order to make it more effective with less obstacles.

[...] we started working on the issue of network care [...] it is something that is being sensitized [...] integration among the team, in this care network [...]. (IN - G 4)

There is a great difficulty, sometimes you notice a great difficulty in knowing SUS, perhaps because you think you do not have as much responsibility as you should [...]. (IN - C 15)

\section{Normative integration}

\section{Cooperation between professionals to obtain continued care}

It is obtained from the norms set out in protocols and which describe how professionals should act in certain situations, especially considering the needs of an individual with a chronic disease, which requires several professionals. Such cooperation does not mean that professionals work continuously in a team, but, when assisting an individual who demands care, they do not hesitate to seek help from another professional. The service portfolio and the protocols used to care for diabetes and hypertension stand out.

In this context, the care model carried out by Family Health Strategy teams stands out. Another important aspect is Family Health Support Centers (NASF - Núcleos de Apoio à Saúde da Família), which stand out in all units for their work and the way they conduct care. The difficulty in cooperation between professionals stems from the lack of preparation and lack of knowledge of this dynamic, both with regard to NASF and teamwork activation.

[...] NASF, a group of professionals who were gradually inserted into PHC to legitimize comprehensive care for the patient and the population [...]. (IN -G 1)

Here is a basic unit, there is the morning team and the afternoon team, there is this separation, there is not much interaction between one team and the other [...]. (IN -N 8)

Service Portfolio: recommends the priority in serving people and reinforces health care for individual-centered care (FC).

Guidelines for care for people with Type 2 Diabetes and Manual of hypertensive patients: systematize and organize care (CF).

\section{Informal coordination mechanisms are essential}

In the absence of a coordinator, another professional assumes this role in a consensual and informal way. The local coordinators recognize the need to provide space for a potential informal coordinator to develop skills favorable to their performance, becoming a reference for the local coordinator and the team, favoring a good progress of services and a good service to CNCDs.

Nurses stand out as professionals who, in the absence of a formal coordinator, perform administrative functions and are the link with HD. Despite the above, some professionals do not recognize the existence of these coordination and professionals who can be that reference, they only recognize the functions formally established.

I believe that all teams have an informal coordinator, nurses are natural leaders [...] when there is no nurse, the team is a little lost. (IN -C 1)

In fact, I don't know how to tell [...] you only the coordinators who are on paper [...]. (IN -C 9)

\section{Care with a focus on users is an important norm and guides the behavior of professionals and services}

Actions must meet users' health needs. Therefore, HD has a network that contributes to the effectiveness of care and seeks to prioritize quality and continuous care.

With regard to $C N C D$, greater emphasis is given to patients with diabetes, hypertension and the elderly, given their vulnerability and risk factors for CNCD. In order for the focus on users to be consistent with the municipality's purpose, there is concern with the way in which professionals act. Coordinators, including nurses, are important links between health unit and HD, and an important strategy for the continuity of care. Furthermore, the advanced access booklet deals with easier access for users; therefore, aspects that enable a more dynamic agenda for health professionals are discussed, in addition to other means that facilitate access to users, such as scheduling appointments.

On the other hand, management changes are examples of situations that cause shock in professional relationships, impairing the service recommended with a focus on users, because in each management, conducts are reviewed and professionals are resized to functions previously performed by others.

[...] the basis of our care, of our essence, is care, because we have the look of technology, of the administrative part, but our focus is on users [...]. (IN - G 1)

[...] users are not to blame for being in this profession for twenty years [...] this management that is there to prune many things [...]. (IN - N 10)

Advanced access booklet - discusses the access and organization of the professionals' agenda. Access needs to be facilitated, so that users can get assistance when they look for it (CF).

\section{Functional integration}

\section{Health District management favors meeting health needs}

Annual Operating Plans (AOP) are management tools that allow operationalizing the goals discussed with health teams based on the population's needs, providing an understanding of what can or cannot affect quality of care. This document supports planning the actions to be carried out; however, its follow-up is not static and is conditioned to the commitment of all parties involved. Managers must be facilitators of actions, promoting dialogue, meetings, establishing priorities for the fulfillment of AOP. 
In each HD there is an equivalent of the Municipal Department, so that the population has access to services they need near their home and is attended to in their need. HD management comprises the director, the coordination in charge of health management, care and surveillance, which enable the progress of services from material aspects, professionals to structural conditions, allowing the flow of service to users and meeting their needs. Some reports suggest less management involvement with the units.

[...] the District gives support to us in the units, so it is a facilitator in the middle of the path, it is he who receives the information from the department [...] it is a circle [...] everything is interconnected [...]. (IN-C 1)

[...] you need something you don't know who the person in charge is, you don't even know if you have a responsible sector [...]. (IN -N 10)

Annual Operating Plan: management tool that favors the operationalization of the goals discussed with the teams (CD).

\section{Decisions by professionals consistent with the care project}

Comprehensive user care is the final and initial route of decisions taken in professional interactions, whether in formal meetings such as the collegiate of $\mathrm{HD}$, during the service to a user or even in informal discussions about a specific case. In all actions that involve caring for chronically ill patients, being the initial route, it triggers planning actions to be developed, and as the final route, it establishes parameters for assessing what has been done. However, the lack of involvement with some situations that requires decision-making by professionals generate dissatisfaction and work overload for some coordinators, hindering continuity of care.

[...] / understand management as a very participative management [...] all the processes that are changed [...] everyone at some point participated in this definition [...]. (IN -C 1)

[...] the nurses here still have difficulty making decisions. Demands a lot for me as coordinator [...]. (IN -C 13)

\section{Information system allows providing services favorable to continuity of care}

The e-Health information system is mentioned as an important strategy to connect $\mathrm{HD}$, linking to teams and establishing connections between professionals and users, through the records of services provided. It allows HD coordination to obtain information that allows them to adapt to the reality of the population through indicators, accomplished goals, as well as all useful information available.

Despite these positive factors, the system does not integrate the entire care network in the municipality. The HD devices that are interconnected through e-health are able to handle some needs; for others, the telephone and e-mail are also recognized as tools conducive to communication. However, most complaints related to e-health and reproduced by professionals in this study were related to difficulty of communication between all services in the network.

[...] we work with e-health and everything is registered there, so if he goes through ECU we have access, he comes from there to continue the unit [...]. (IN-N 14)
[...] we do not have access to other services [...] only what is inside the city hall [...] if it went to a hospital, I don't know what happened [...]. (IN -C 13)

Field diary: Notes to corroborate information from other data sources (CD).

Zimbra: institutional email and through which information is exchanged between professionals (CD).

\section{User management service}

The municipality's ombudsman service can be used by the portal or telephone by users as a tool for interacting with health services, issuing opinions, making complaints, all so that their level of satisfaction regarding the service received is known.

[...] it has an information system for satisfying the care of our population, which is the ombudsman [...]. Ombudsman is a very rich tool that is open to the community, the community can call there, criticize, praise or suggest. (IN - G2)

Advanced access booklet - with this document users can learn about the discussions involving service flows (CF).

Municipal portal (Central 156) - ombudsman receives and analyzes users' statements, identifies demands, analyzes the decision made, provides user feedback and guidance on services offered, etc. (CF).

\section{DISCUSSION}

This study contributes to the recognition of CNCD care strategies in systemic, normative and functional dimensions, with an emphasis on coordination, HD organization, AOP, information system and user management service, from the perspective of a theoretical framework that considers integrated care a viable way to overcome many health-related problems.

Nation and worldwide Health Systems, despite their differences in terms of funding, organization and management, are affected in similar ways with regard to financial resources, the increase in the older population, CNCD incidence, among other aspects ${ }^{(7,15-18)}$. In order to continue offering quality services, governments need to significantly restructure their health systems ${ }^{(7)}$; and, among other aspects, it is important to advance in the development of actions that integrate and articulate the various services, so that coping with CNCDs is carried out transversally ${ }^{(19)}$.

Creating public policies with a focus on prevention and care for CNCDs is among the greatest challenges for SUS. The characteristics of these diseases comprise an uncertain duration and high rates of morbidity and mortality, requiring increasingly longitudinal and comprehensive care, involving, in addition to treatment, prevention and promotion actions $s^{(5,20)}$. Therefore, integrated care is essential as health needs demand more complex care that cannot be accessed in a single place or performed by a professional, taking into account its limitations in time and space ${ }^{(7)}$.

Systemic integration is enhanced in coherence at all levels of assistance; therefore, its viability is linked to the result between the relationships between the various services and between 
professionals and in their decision-making, as well as in the relationships established between professionals and users ${ }^{(7,11)}$. The concept of network service is relatively new for the professionals in this study in question. The role of PHC as the coordinator of care has been gradually emphasized in $\mathrm{HD}$, coinciding with autonomy and responsibility conferred on health units with regard to care focused on comprehensive care ${ }^{(11)}$.

The networks do not emerge from a vacuum, but are linked to a context in which the various actors negotiate their interactions; to do so, they must be surrounded by conditions that favor collaboration. Among these, the distribution of power affects the dynamics of the network. Therefore, coordination within HD has considerable importance for reorganizing care processes, considering their autonomy, decision-making capacity and skills in dealing with other professionals. ${ }^{(11,15,17,21)}$.

Society's demands, needs and inequalities influence the formulation of public policies; likewise, the executive branch can influence the creation of an adequate space for norms related to such policies. All professionals, as well as the society itself, communicate with the system through integration strategies. The electronic media are mainly read as websites, electronic correspondence etc. HD follows the norms dictated by the municipality, which follows the norms formatted in the Health System. Thus, the knowledge related to SUS guidelines supports performance of health actions by professionals ${ }^{(11,22)}$.

In other words, normative integration aims to guarantee a logic between the system of representations and values of society with the other dimensions, resulting in a context where there is adequate communication between all involved ${ }^{(7,11)}$. Normative integration allows to unify all contexts within HD and goes beyond that, allowing it to be linked to the Health System and to all Health System levels among themselves. It is a dimension of integration that is not very tangible, which seems to be bordering on something far from reality, but it is essential to facilitate collaboration and ensure consistency among all. To ensure this logic that allows to unite values, service organization and the clinical system, normative integration must be shaped and based on professional behaviors and attitudes ${ }^{(7-8,11)}$.

For this reason, informal coordination mechanisms, as well as care focused on each individual, are so important. This last aspect is a social norm. As such, it should guide professionals' behaviors within a health system and may also favor coordination in $\mathrm{HD}^{(8,11)}$.

Changes in the context of health systems have caused difficulties in adapting health services and professionals working in them, and, consequently, in responding appropriately to these changes ${ }^{(23)}$. Among these changes, attention to chronic diseases implies the prevention of complications and holistic, comprehensive and multidisciplinary care. The nursing profession also evolves with such changes, and with them, new attributions are given to the nurse. In this sense, the priorities of health systems must be focused on strategies, with clear proposals for coordination and continuity of care; definitions of the roles of each professional, incorporation of tools and technologies; attention to scientific evidence with practical improvement; skills acquisition and involvement with decision-making ${ }^{(3)}$.

In this regard, considering also the need for mechanisms that favor coordination ${ }^{(7)}$, the insertion of nurses in this context of coping with CNCDs may be favorable. The coordination skills of care, inherent to their work process ${ }^{(3,23-26)}$ can be a strategy for comprehensive care, with the potential to minimize barriers between care levels ${ }^{(11)}$.

HD follows an organization that comprises several coordination. All coordination within an institution is an inherent aspect of integration. Coordination represents a tool that allows examining and adjusting the relationships between everyone, which can promote articulation and as a result expand the possibilities of care centered on individuals' health needs, a collective project that should support all professional actions $s^{(7,11)}$.

In the municipality of the study in question, since 2002 ended, management contracts have been established between health units and HD and these with the Municipal Department. With that being said, all action planning must be based on AOP, elaborated based on the peculiarities of each territory; therefore, they aim to carry out actions that meet individuals' health needs. The coordinators, here understood equally as managers, must be facilitators of these actions, promoting dialogue, meetings, establishing priorities so that this plan is fulfilled and its closing is done appropriately ${ }^{(11,27)}$ and in due time.

The municipality grants autonomy to HD to implement technologies and manage the population's health in its territory; in this line, health units organize themselves to assist CNCDs either by assisting through programs or in a less regulated way, with free access. However, it is only possible to engender actions that reflect on satisfactory service to users with CNCD when all professionals have consistency in their care practices. Otherwise, without professional involvement, there is difficulty for continuity of care. There is always a conflicting polarization in the context in which care takes place; there is professional engagement, but it is also difficult to act on behalf of users' needs ${ }^{(11)}$.

Functional integration favors the clinic and the interaction between professionals, and refers to all the mechanisms and tools available that allow care to occur. Thus, one can overlap the dimension of functional integration in the space where the greatest HD decisions are centralized and in which management, care and health surveillance coordination are concentrated ${ }^{(7-8,11)}$. However, functional integration does not mean more centralization or standardization, it must be a flexible approach, allowing partnerships between professionals and between service providers with HD, so that they adapt to the population's needs ${ }^{(8,11)}$. Coordination and all its activities or even the connections established between all professionals are favored, when guided by an agile and flexible information system ${ }^{(11,17)}$, which allows decision-making on responsibilities, attributions and financial resources ${ }^{(11)}$.

All of these aspects are favorable to quality assistance, as well as mechanisms that guide individuals, so that they can enjoy services and feel important within the Network, as a user management service, which provides access to information from the municipality, being a means for users interact with services ${ }^{(11)}$.

Considering these notes, it is learned that the functional integration in HD is inherent to meeting individuals' health needs, through an organization favorable to the functioning of HD. All the logistics understood are included, from the composition of managers to the way HD is inserted and articulated in the network - care is made possible and carried out in possible situations ${ }^{(11)}$. 
The theoretical framework used favored understanding the impact of strategies on integrated care for individuals affected by chronic diseases, especially for emphasizing coordination as something intrinsic to this context.

The concept used for integration recognizes that it is possible for a society to maintain the same level of equality among all, respecting the freedom and autonomy of each one, with efficiency with regard to physical, professional, economic and service management resources. Although it is challenging, since equality, freedom and efficiency are subject to mismatch, the health system is capable of providing quality care to CNCDs. Another circumstance that must be taken into account is the need for increasingly integrated care to obtain a level of excellence in care, while allowing an organization of economic resources ${ }^{(7)}$.

Finally, some weaknesses pointed out by the study related to assistance organization, professional interactions, as well as aspects related to service management and which make it impossible to meet all the population's needs, could be overcome with valorization, improvement and spread to others health system scenarios of the strategies indicated, such as coordination, which proved to be solid and with undeniable importance in HD.

\section{Study limitations}

It was not possible to point out strategies in all dimensions. For this reason, we chose to highlight the three dimensions present in this article, in order to carry out a more in-depth analysis.

\section{Contributions to nursing and health}

Regardless the lens used to analyze a context, health professionals must make sense of their daily practices in order to be able to implement them. It is inferred that coordination, especially the human work they represent, stood out as important tools for health professionals - among them nurses - and that contribute to obtaining more continuous and higher quality care.

\section{FINAL CONSIDERATIONS}

HD comprises a structure that allows interactions between everyone through various tools to ensure adequate functionality. In this regard, the systemic, normative and functional dimensions pointed to integration strategies that can favor attention to CNCDs. The work carried out by the coordination, HD organization, informal coordination, AOP, information system and user management service stood out.
HD organization and coordinators' work facilitate access to health services. In this sense, coordination is an effective strategy to enhance network care, especially when it encourages cooperation between professionals, optimizing care and translating, therefore, into support and management for HD. It is noteworthy that the nurse is not the only professional who can exercise coordination in HD. However, the greater number of coordinators with this training and the aspects recovered in this study are indicative that this professional has a remarkable managerial capacity to exercise different positions and functions, including informal coordination. The information system promotes articulation between health professionals and services, an essential aspect for care within CNCDs. On the other hand, the path of individuals to services outside of HD requires greater commitment from professionals, considering that the same system is not operating in the entire network. User management service is an important communication channel between the population and the services, favoring care knowledge. Finally, AOP represents an important tool so that care can be offered with quality, recognizing the various needs of people with CNCDs.

In order to provide comprehensive care, several arrangements are required throughout the system, with favorable policies that prioritize quality care. Moreover, the integration strategies identified only make sense with professionals committed to a care logic in which care is coordinated according to each person's health needs.

\section{FUNDING}

This study is part of a multicenter project coordinated by Prof. Dr. Elizabeth Bernardino entitled "Estratégias de Integração em Rede: Contribuições do Enfermeiro", presented to the Graduate Program in Nursing at Universidade Federal do Paraná (PPGENF/ UFPR), financed by the public notice the Brazilian National Council for Scientific and Technological Development (CNPq - Conselho Nacional de Desenvolvimento Científico e Tecnológico). This work was carried out with the support of the Coordination for the Improvement of Higher Education Personnel - Brazil (CAPES Coordenação de Aperfeiçoamento de Pessoal de Nível Superior) - Financing Code 001.

\section{ACKNOWLEDGMENT}

We would like to thank the professionals who participated in this study, and Prof. Dr. André-Pierre Contandriopoulos, for the theoretical support and promptness to answer our questions at the beginning of this research.

\section{REFERENCES}

1. Secretaria de Vigilância em Saúde, Ministério da Saúde. Portaria № 4.279, de 30 de dezembro de 2010: Estabelece diretrizes para a organização da Rede de Atenção à Saúde no âmbito do Sistema Único de Saúde (SUS) [Internet]. Brasília: Ministério da Saúde; 2010 [cited 2019 Mar 11]. Available from: http://conselho.saude.gov.br/ultimas_noticias/2011/img/07_jan_portaria4279_301210.pdf

2. Duarte EC, Barreto SM. Transição demográfica e epidemiológica: a Epidemiologia e Serviços de Saúde revisita e atualiza o tema. Epidemiol Serv Saúde. 2012; 21:529-32. doi:10.5123/S1679-49742012000400001

3. Gómez-Picard P, Fuster-Culebras J. Atención a lacronicidad: desafio estratégico, macrogestión y políticas de salud. Enferm Clin. 2014;24:12-7. doi: 10.1016/j.enfcli.2013.12.001 
4. Mascarenhas MDM, Barros MBA. Evolução das internações hospitalares por causas externas no sistema público de saúde: Brasil, 2002 a 2011. Epidemiol Serv Saúde. 2015;24:19-29. doi: 10.5123/S1679-49742015000100003

5. World Health Organization (WHO). World health statistics 2018: Monitoring health for the sustainable development goals [Internet]. Geneva; 2018 [cited 2019 Mar 11]. Available from: https://www.who.int/gho/publications/world_health_statistics/2018/en/

6. Armitage GD, Suter E, Oelke ND, Adair C. Health Systems Integration: state of evidence. Int J Integr Care. 2009;17:e82. doi: 10.5334/ijic.316

7. Contandriopoulos AP, Denis JL, Touati N, Rodriguez R. Intégration des soins: dimensions et mise en œuvre. Ruptures, Rev Transdiscip Santé [Internet]. 2001 [cited 2019 Jun 7];8(2):38-52. Available from: http://www.medsp.umontreal.ca/ruptures/pdf/articles/rup082_038.pdf

8. Valentijn PP, Schepman SM, Opheij W, Bruijnzeels MA. Understanding integrated care: a comprehensive conceptual framework based on the integrative functions of primary care. Int J Integr Care. 2013;13:e010. doi:10.5334/ijic.886

9. Valentijn PP, Boesveld IC, Klauw DM, Ruwaard D, Struijs JN, Molema JJW et al. Towards a taxonomy for integrated care: a mixed-methods Study. Int J Integr Care. 2015;15:e003. doi: 10.5334/ijic.1513

10. Evans JM, Baker GR, Berta W, Barnsley J. A cognitive perspective on health systems integration: results of a Canadian Delphi study. BMC Health Serv Res. 2014;14:222. doi: 10.1186/1472-6963-14-222

11. Sousa SM. Contribuição do enfermeiro na integração dos cuidados no contexto das Doenças Crônicas não Transmissíveis [Tese]. Curitiba: Universidade Federal do Paraná; 2019.

12. World Health Organization (WHO). Integrated health services: what and why? Technical Brief [Internet]. Geneva, 2008 [cited 2019 Mar 11$].$ Available from: https://www.who.int/healthsystems/technical_brief_final.pdf

13. Yin RK. Estudo de caso: planejamento e métodos. 5 ed. Porto Alegre: Bookman. 2015.

14. Tong A, Sainsbury P, Craig J. Consolidated criteria for reporting qualitative research (COREQ): a 32-item checklist for interviews and focus groups. Int J Qual Health Care. 2007;19(6):349-57. doi: intqhc/mzm042

15. Rodríguez C, Contandriopoulos AP, Larouche D. Implementation evaluation of an integrated healthcare delivery initiative for diabetic patients. Healthcare Policy [Internet]. 2006 [cited 2019 Mar 03];1:99-120. Available from: https://www.ncbi.nlm.nih.gov/pmc/articles/ PMC2585338/pdf/policy-01-99.pdf

16. Malta DC, França E, Abreu DMX, Perillo RD, Salmen MC, Teixeira RA, et al. Mortality due to noncommunicable diseases in Brazil, 1990 to 2015, according to estimates from the Global Burden of Disease study. Sao Paulo Med J. 2017;135:213-21. doi: 10.1590/1516-3180.2016.0330050117

17. Almeida PF, Oliveira SC, Giovanella L. Network integration and care coordination: the case of Chile's health system. Ciênc Saúde Coletiva. 2018;23:2213-28. doi: 10.1590/1413-81232018237.09622018

18. Saldiva P, Veras M. Gastos públicos com saúde: breve histórico, situação atual e perspectivas futuras. Estud Avanç. 2018;32:47-61. doi: 10.5935/0103-4014.20180005

19. Malta DC, Oliveira TP, Santos MAS, Andrade SSCA, Silva MMA. Progress with the strategic action plan for tackling chronic non-communicable diseases in Brazil, 2011-2015. Epidemiol Serv Saude. 2016;25:373-90. doi: 10.5123/s1679-49742016000200016

20. Malta DC, Moura L, Prado RR, Escalante JC, Schmidt MI, Duncan BB. Mortalidade por doenças crônicas não transmissíveis no Brasil e suas regiões, 2000 a 2011. Epidemiol Serv Saúde. 2014;23:599-608. doi: 10.5123/S1679-49742014000400002

21. Kalichman AO, Ayres JRCM. Integralidade e tecnologias de atenção à saúde: uma narrativa sobre contribuições conceituais à construção do princípio da integralidade no SUS. Cad Saúde Pública. 2016;32:e00183415. doi: 10.1590/0102-311X00183415

22. Pinto Jr VC, Cavalcante RC, Branco KMC, Cavalcante TMB, Maia ICL, Souza NMG, et al. Proposal of an integrated health care network system for patients with congenital heart defects. Braz J Cardiovasc Surg. 2016;31:256-60. doi: 10.5935/1678-9741.20160056

23. Miguélez-Chamorro A, Ferrer-Arnedo C. La enfermera familiar y comunitaria: referente del paciente crónico em la comunidade. Enferm Clín. 2014;24:5-11. doi: 10.1016/j.enfcli.2013.12.002

24. Cass S, Ball L, Leveritt M. Australian practice nurses' perceptions of their role and competency to provide nutrition care to patients living with chronic disease. Aust J Prim Health. 2014;20:203-8. doi: 10.1071/PY12118

25. Hoepfner C, Franco SC, Maciel R A, Hoepfner AMS. Programa de apoio matricial em cardiologia: qualificação e diálogo com profissionais da atenção primária. Saude Soc. 2014;23(3):1091-101. doi:10.1590/S0104-12902014000300028

26. Ribas EN, Bernardino E, Larocca LM, Poli Neto P, Aued GK, Silva CPC. Nurse liaison: a strategy for counter-referral. Rev Bras Enferm. 2018;71:546-53. doi:10.1590/0034-7167-2017-0490

27. Bazzo-Romagnolli AP, Gimenez-Carvalho B, Almeida-Nunes EFP. Gestão de unidade básica de saúde em municípios de pequeno porte: instrumentos utilizados, facilidades e dificuldades relacionadas. Rev Gerenc Polít Salud. 2014;13:168-180. doi: 10.11144/Javeriana. rgyps13-27.gubs 